and lignocaine may be used by the intravenous route to suppress these arrhythmias, but why one morphological type of ventricular ectopic will respond to one of the above antiarrhythmic drugs and not to another remains to be studied. Currently, lignocaine is the drug of choice because of its high therapeutic effect compared with its relatively slight negative inotropic effect. It is used in incremental doses up to $200 \mathrm{mg}$.

\section{Summary}

Thirty-one patients with cardiac arrhythmias were treated with beta-adrenergic blocking drugs propranolol and pronethalol. Propranolol was found to be panticularly useful in the management of rapid arrhythmias when other antiarrhythmic drugs had not been successful. Beta-adrenergic blockade was of value in reducing the ventricular rate in paroxysmal atrial fibrillation, atrial flutter, and rapid atrial and sinus rhythms. Propranolol also possessed a specific antiarrhythmic effect not clearly related to its beta-adrenergic blocking effect, and was found to be useful in the treatment of ventricular extrasystoles, paroxysmal ventricular tachycardia, ventricular arrhythmias associated with digitalis intoxication, and recurrent and resistant ventricular fibrillation.

Forty-nine (26 treated, 23 control) patients with acute myocardial infarction were studied to assess the prophylactic value of propranolol in reducing arrhythmias in acute myocardial infarction. The drug was administered intravenously initially in a dose of $0.1 \mathrm{mg}$. $/ \mathrm{kg}$./body weight together with atropine sulphate $1.2 \mathrm{mg}$. followed by $10 \mathrm{mg}$. of propranolol orally four-hourly for three weeks. There was no difference in the incidence of arrhythmias between the two groups.
Our thanks are due to the medical staff, Royal Melbourne Hospital, who allowed us to treat patients under their care. The propranolol used in this study was made available by Dr. Charles Proctor (Medical Director, I.C.I., Australia), to whom we are grateful. Mr. J. R. Bainbridge, Computer Centre, Monash University, advised on the statistical treatment of the results from the coronary care ward.

\section{REFERENCES}

Balcon, R., Jewitt, D. E., Davies, J. P. H., and Oram, S. (1966). Lancet, 2, 917

Barber, J. M., Murphy, F. M., and Merrett, J. D. (1966). Ibid., 2, 1079. Cherchi, A., Lixi, M., Mazza, B., and Camoglio E. (1966). Minerva med., 57, 317.

Clausen, J., Felsby, M., Jørgensen, F. S., Nielsen, B. L., Roin, J., and Strange, B. (1966). Lancet, 2, 920.

Epstein, S. E., and Braunwald, E. (1966). New Engl. Ұ. Med., 275, 1106, 1175 .

Gettes, L. S., and Surawicz, B. (1966). Circulation, 34, Suppl. No. 3. p. 109.

Harris, A. (1966). Amer. F. Cardiol., 18, 431

Harrison, D. C., Griffin, J. R., and Fiene, T. J. (1965). New Engl. 7 Med., 273, 410 .

Howe, R., and Shanks, R. G. (1966). Nature (Lond.), 210, 1336.

Luria, M. H.; Adelson, E. I., and Miller, A. J. (1966). Circulation, 34, 767.

Payne, J. P., and Senfield, R. M. (1964). Brit. med. 7., 1, 603.

Pentecost, B. L. (1966). Lancet, 2, 1078.

Rochet, J., and Vastesaeger, M. M. (1966). Scalpel (Brux.), 119, 267.

Sloman, G., Robinson, J. S., and McLean, K. (1965). Brit. med. F., 1, 895.

Snow, P. J. D. (1965). Lancet, 2, 551.

Stickney, J. L., Lucchesi, B. R., and Abrams, G. D. (1966). Fed. Proc.,

25, 621.

Stock, J. P. P. (1966). Amer. F. Cardiol., 18, 444.

Szekely, P., Jackson, F., Wynne, N. A., Vohra, J. K., Batson, G. A., and Dow, W. I. M. (1966). Amer. f.' Cardiol., 18, 426.

Vaughan Williams, E. M. (1963). Amer. Heart f., 66, 569

Wolfson, S., Robbins, S. I., and Krasnow, N. (1966). Ibid., 72, 177.

\title{
Serum Folate Values in 423 Psychiatric Patients
}

\author{
M. W. P. CARNEY,* M.D., M.R.C.P.I., D.P.M.
}

With the widespread introduction of efficient ways of estimating serum folate, there have been reports of folate deficiency in malnutrition (Gough et al., 1963), old age (Read et al., 1965), a number of chronic physical illnesses (Batata et al., 1967), neurological disease (Grant et al., 1965), and patients receiving anticonvulsants, barbiturates (Klipstein, 1964 ; Malpas, 1966), antibiotics, and cytotoxic agents (Dr. E. J. Watson-Williams, personal communication). Folate deficiency and psychiatric conditions have also been associated-for example, anxiety/ depression (Gough et al., 1963) and dementia (Henderson et al., 1966)-while 12 out of 43 patients with subnormal serum folate were currently attending a psychiatric department (Forshaw, 1965). Reynolds $(1966,1967)$ has gone so far as to suggest a causal relation between folate deficiency and certain forms of mental illness, especially affective changes and, in long-standing cases, dementia. There seems, however, to have been little systematic investigation of the incidence of folate deficiency in psychiatric populations.

These reports encouraged me to ascertain the incidence of low serum folate levels in a psychiatric population and its relation to a number of variables, including diagnosis, age, nutrition, physical state, drugs, and chronicity of illness. Though this investigation was not specifically designed to answer the question, it was felt that some clues regarding the

\footnotetext{
- Consultant Psychiatrist, Blackpool and Fylde Hespital Group and Lancaster Moor Hospital,
}

possible aetiological significance of folate deficiency in mental illness might appear.

\section{Method and Material}

Serum folate estimations were carried out on consecutive admissions to two psychiatric units 20 miles $(32 \mathrm{~km}$.) apart, one a general hospital unit and the other a mental hospital. They were all under my personal care and were admitted over a period slightly exceeding a year. Though the hospitals served the same geographical area they dealt with somewhat different psychiatric populations, the mental hospital tending to admit the more disturbed and more chronic patients. The intakes of both units were studied concurrently in order to ensure that the whole group was representative with respect to diagnosis, age, and sex of those psychiatric patients within the catchment area for whom admission to hospital was judged to be needed. Within individual subcategories of patients there was little variation in folate levels between the two hospitals.

Serum folate estimations were carried out by an adaptation of the method of Waters and Mollin (1961) by which folate activity was measured by reading turbidimetrically the growth of Lactobacillus casei A.T.C.C. 7469 after incubation in the sample solution for 48 hours at $37^{\circ} \mathrm{C}$.: the results were calculated from a standard graph. These estimations were carried out in two different laboratories, but the procedures in both were identical. 
Serum folate estimations were also carried out on nursing, medical, and clerical staff, mental welfare officers, and ambulance drivers-all volunteers. These constituted a control series; so far as was known none of them was receiving psychiatric treatment and all appeared to be physically fit.

There were 423 patients of mean age $54.04 \pm 9.61$ (282 females and 141 males). There were 62 controls of mean age $39.2 \pm 12.65$ ( 31 females and 31 males). Patients and controls differed significantly as regards age and sex, but since these factors were not found to be significantly associated with the folate levels within the context of the present investigation, they are probably of little importance. Only one patient had been receiving Cytamen (cyanocobalamin) previous to admission, none had received folic acid, and none was diagnosed as suffering from subacute combined degeneration of the cord.

Because of the undoubted influence of certain drugs in lowering the serum folate, blood was obtained as soon as possible after admission and nearly always before treatment was begun. Simultaneously, samples were sent to the laboratory for vitamin. $B_{12}$ estimations. This paper does not deal with the breakdown of the $B_{12}$ results except where they seem to be relevant to the folate findings.

\section{Results}

The mean serum folate for the patients was $3.2 \pm 1.73 \mathrm{~m} \mu \mathrm{g}$./ $\mathrm{ml}$. and for the controls $3.6 \pm 1.5 \mathrm{~m} \mu \mathrm{g} . / \mathrm{ml}$. This difference is not quite significant $(t=1.92 ; \mathrm{P}>0.05)$. However, Fig. 1 shows a distinct clustering of the patients at the lower end of the scale not matched by the controls. If a folate level of $2 \mathrm{~m} \mu \mathrm{g} . / \mathrm{ml}$. is taken as the dividing point, there are only six controls as against 105 patients below this point. This difference is significant at the $1 \%$ level $\left(x^{2}=6.89 ;\right.$ d.f. $\left.=1\right)$. Values of serum folate bclow $2 \mathrm{mug}$. $/ \mathrm{ml}$. are hereafter referred to as "low folate."

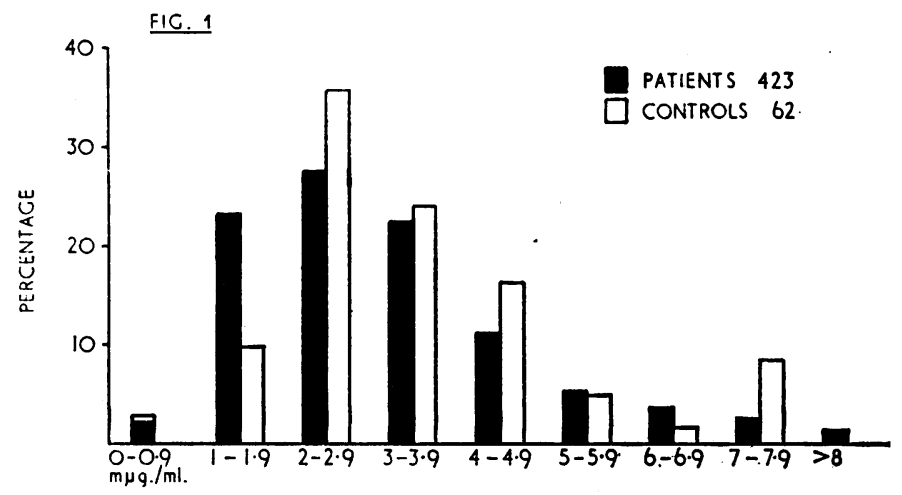

Fig. 1.- Serum folate levels: psychiatric patients compared with normal controls.

Age.-Depressed folate levels have often been found in geriatric patients. The relation between various age groups and their mean folate values is shown in Table I. There is obviously

Table I.-Mean Serum Folate' Levels for Various Age Groups

\begin{tabular}{c|c|c|c|c|c|c|c|c}
\hline & \multicolumn{7}{|c}{ Age in Years } \\
\hline & $10-29$ & $30-$ & $40-$ & $50-$ & $60-$ & $70-$ & $80+$ & $\begin{array}{c}\text { Overall } \\
\text { Mean }\end{array}$ \\
\hline $\begin{array}{c}\text { Mean serum } \\
\text { folate } \\
(\mathrm{m} \mu \mathrm{g} . / \mathrm{ml} .)\end{array}$ & 3.2 & 3.6 & 3.1 & 3.4 & 3.0 & 3.0 & 3.1 & 3.2 \\
\hline
\end{tabular}

no constant relation here. The mean ages of the low $(53.8 \pm$ 17.6) and normal folate $(54.3 \pm 17.12)$ patients did not differ significantly.

Sex.-The sex distribution did not alter with the serum folate level.
Haematological Findings.-A full blood count was made and a blood film taken in all patients. Of those with low folate values, 28 had haemoglobins of less than $80 \%$ and five had other abnormalities such as anisocytosis. Thus $33(31.4 \%)$ of these patients had a haematological abnormality ; of these seven showed macrocytosis and three had a low serum $B_{12}$. On the other hand, only $33(10.7 \%)$ of patients with normal folate results had a haemoglobin below $80 \%$ or showed abnormality, and none had macrocytosis. The difference between the two groups is significant $\left(\chi^{2}=24.94\right.$; d.f. $\left.=1 ; \mathrm{P}<0.001\right)$.

Sternal Marrow.-A very small number of patients with evidence of anaemia, etc., were given sternal marrow puncture and a specimen of marrow was examined. Only one of these was unequivocally megaloblastic and this patient, besides having a serum folate of $1.2 \mathrm{~m} \mu \mathrm{g} . / \mathrm{ml}$., also had a serum $B_{12}$ of less than $25 \mu \mu \mathrm{g} . / \mathrm{ml}$. Thus in the present study no certain evidence of megaloblastic marrow change was found to be associated with a low folate value. This does not mean that megaloblastic marrow would not have been found if more sternal punctures had been performed. Obviously there is a limit to the frequency of this uncomfortable and sometimes frightening procedure in the psychiatric setting. Moreover, many of these patients were not very co-operative.

Folate Deficiency and Serum Vitamin $B_{12}$.-There have been reports that folate deficiency has resulted in subnormal serum $B_{12}$ levels with a return to normal after administration of folic acid (Forshaw et al., 1964). In 368 of the present patients the serum $B_{12}$ result was available and there seems to be an association between the lower values of serum folate and a serum $B_{12}$ level below $150 \mu \mu \mathrm{g} . / \mathrm{ml}$. (hereafter called "low" $\mathrm{B}_{12}$ ) (Table II). Patients with serum folate less than $2.9 \mathrm{~m} \mu \mathrm{g} . / \mathrm{ml}$. are significantly more liable to low serum $B_{12}$ than otherwise $\left(\chi^{2}=\right.$ $4.15 ;$ d.f. $=1 ; \mathrm{P}<0.05)$. This finding, apart from its theoretical interest, is of practical importance. It has long been recognized that folic acid therapy in the presence of clinically occult vitamin $B_{12}$ deficiency can precipitate subacute combined degeneration. It seems prudent, therefore, to assess the vitamin $B_{12}$ status of folate-deficient patients before embarking on folic acid therapy.

TABLB II.-Incidence of Low Serum Vitamin $B_{1_{2}}(<150 \mu \mu \mathrm{g} . / \mathrm{ml}$.) for Various Levels of Serum Folate

\begin{tabular}{cc|c|c|c|c}
\hline $\begin{array}{c}\text { Serum Folate } \\
(\mathrm{m} \mu \mathrm{g} . / \mathrm{ml} .)\end{array}$ & $\begin{array}{c}0-1.5 \\
(\mathrm{n}=56)\end{array}$ & $\begin{array}{c}1.6-1.9 \\
(\mathrm{n}=46)\end{array}$ & $\begin{array}{c}1.9-2.9 \\
(\mathrm{n}=100)\end{array}$ & $\begin{array}{c}>2.9 \\
(\mathrm{n}=166)\end{array}$ \\
\hline Patients with low $\mathrm{B}_{12}(\%)$ & $\cdots$ & 21.4 & 15.2 & 15 & 10.2 \\
\hline
\end{tabular}

\section{Psychiatric Diagnosis}

Table III shows the patients classified into diagnostic groups with mean ages, ranked in order of magnitude of mean serum folate. There is no corresponding progression of age, confirming that there is no clear-cut relation between serum folate and age. The following diagnostic groups have significantly lower

TABLB III.-Diagnostic Groups: Mean Ages and Mean Folate Leods Compared with Mean Folate Level for Controls $(3.6 \pm 1.5 \mathrm{m \mu g} / \mathrm{ml}$.)

\begin{tabular}{|c|c|c|c|c|c|}
\hline \multirow{2}{*}{ Diagnosis } & \multirow{2}{*}{ No. } & \multirow{2}{*}{$\begin{array}{c}\text { Age } \\
\text { (years) }\end{array}$} & \multirow{2}{*}{$\begin{array}{c}\text { Serum } \\
\text { Folate } \\
(\mathrm{m} \mu \mathrm{g} . / \mathrm{ml} .)\end{array}$} & \multicolumn{2}{|c|}{ Significance } \\
\hline & & & & $\boldsymbol{t}$ & $\mathbf{P}$ \\
\hline $\begin{array}{l}\text { Chronic alcoholism } \\
\text { Mania } \\
\text { Drug addiction }\end{array}$ & $\begin{array}{l}27 \\
18 \\
12 \\
78 \\
30\end{array}$ & $\begin{array}{l}46 \cdot 4 \\
54 \cdot 0 \\
47 \cdot 5 \\
41 \cdot 8 \\
48 \cdot 9 \\
47 \cdot 7 \\
34 \cdot 5 \\
55 \cdot 0 \\
72 \cdot 9 \\
47 \cdot 5\end{array}$ & $\begin{array}{l}6.3 \pm 3.0 \\
4.1 \pm 2.0 \\
3.5 \pm 1.6 \\
3.4 \pm 1.6 \\
3.3 \pm 1.6 \\
3.2 \pm 1.7 \\
3.2 \pm 1.2 \\
3.0 \pm 1.7 \\
2.9 \pm 1.5 \\
1.7 \pm 0.8\end{array}$ & $\begin{array}{l}2 \cdot 3 \\
2 \cdot 7 \\
7 \cdot 2\end{array}$ & $\begin{array}{l}\text { is. } \\
\text { N.S. } \\
\text { N.S. } \\
\text { N.S. } \\
\text { N.S. } \\
\text { N.S. } \\
\text { N.S. } \\
\quad<0.05 \\
<0.01 \\
<0.001\end{array}$ \\
\hline Total & 423 & $54.04 \pm 9.61$ & $3.2 \pm 1.73$ & & \\
\hline
\end{tabular}

N.S. $=$ Not significant. 
mean serum folate values than the controls: epilepsy, organic psychoses, and endogenous depression; the only diagnosis with a mean serum folate significantly above that of the controls is chronic alcoholism.

In elucidating the relation between folate deficiency and psychiatric diagnosis, it was decided to exclude those patients with a low serum vitamin $B_{12}$, as this condition is thought to cause mental illness, and it has just been shown that this could have influenced the clinical picture in patients with the lower serum folate levels. Fig. 2 shows the distribution of patients with low serum folate values and normal serum vitamin $B_{12}$ among the various diagnostic groups ("organic" comprises dementia and delirious/subdelirious states; "others" include neurosis, abnormal personality, mania, drug addiction, and chronic alcoholism). Not unexpectedly, epilepsy has the highest proportion, with, surprisingly, depression next and organic psycho-syndromes coming only third. The distribution of diagnoses among the low folate patients is significantly different from that of patients with normal folate $\left(\chi^{2}=13.55\right.$; d.f. $=4$; $P<0.01$ ). This situation is quite different from the distribution of diagnoses among patients with low serum $B_{12}$ levels, where organic states have a clear lead (Fig. 3).

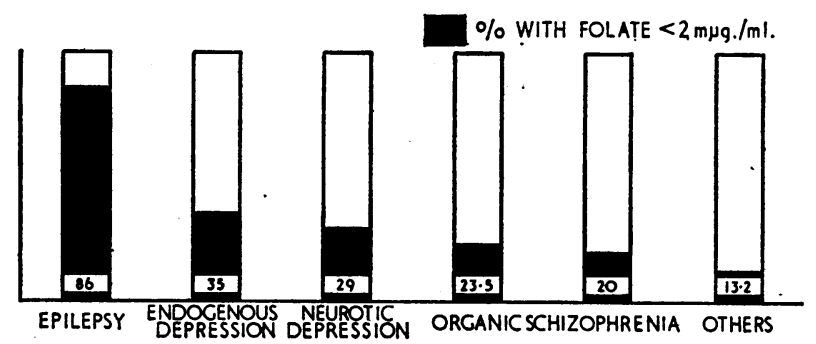

Fig. 2.-Low serum folate levels and psychiatric diagnosis in 317 patients.

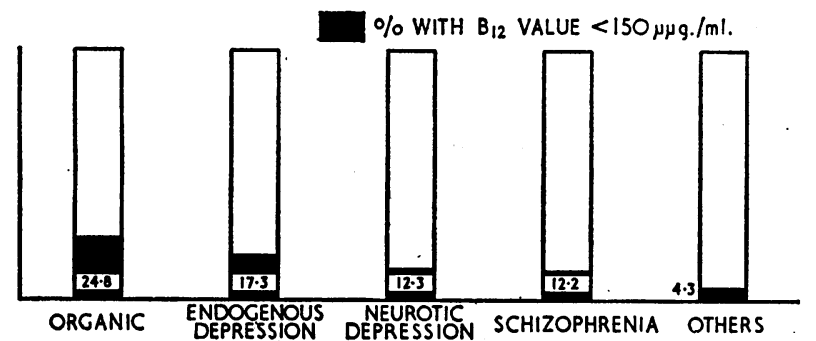

FIG. 3.-Low serum vitamin $B_{12}$ and psychiatric diagnosis in 377 patients.

The 19 patients with both low serum folate and vitamin $B_{12}$ levels tended to conform to the diagnostic pattern of the low serum $B_{12}$ group; thus there were eight organics, four endogenous depressives, three schizophrenics, two neurotic depressives, one other neurotic, and one chronic alcoholic.

\section{Further Study of Low Serum Folate Group}

The patients with low serum folate levels were more intensively studied for other aetiological factors, both by clinical examination and investigation and by social history-taking from relatives, etc., and consultation with the general practitioners. These last were particularly helpful in ascertaining the patients' preadmission medication (if any). The following results all refer to this group:

(a) Drugs.-Of the 105 patients, $79(75 \%)$ had been on drugs in the three weeks before admission. The breakdown of these is presented in Table IV. The figures do not add up, because some patients had more than one drug. They are divided into drugs widely recognized as depressing serum folate and other drugs. Not unexpectedly barbiturates and anticonvulsants predominate among the former and phenothiazines and antidepressants among the latter. Of course any group of psychiatric patients might be expected to show this kind of drug pattern. The appropriate way of demon- strating an association between low serum folate and drugs would be by comparing the preadmission drug intakes of low and normal folate groups. Unfortunately it was not possible to obtain this information for the normal serum folate group, but it was collected for those patients with low serum $B_{12}$. The preadmission drug patterns for both groups are compared in Table V, patients with simultaneous depression of serum folate and $B_{12}$ having been excluded. It is clear that the low folate group have had drugs far more frequently than the low serum $B_{12}$ patients, suggesting that psychotropic drugs are, in some way as yet unclear, associated with low serum folate levels. Of course the variation could be accounted for by other differences between the two groups.

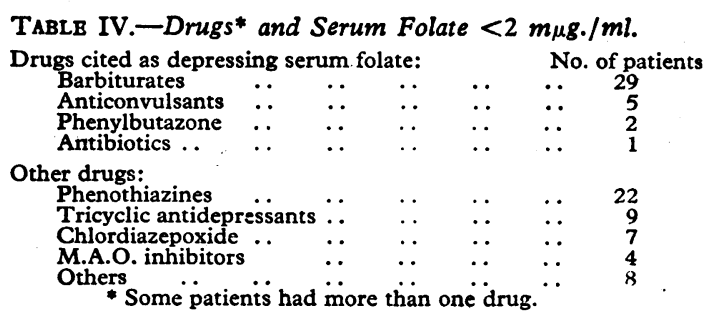

TABLE V.-Drugs and Low Serum Folate and Vitamin $B_{12}$ Levels

\begin{tabular}{|c|c|c|c|}
\hline & No. of Cases & Drugs & No Drugs \\
\hline $\begin{array}{l}\text { Serum folate }<2 \mathrm{~m} \mu \mathrm{g} . / \mathrm{ml} \text {. and } \\
\text { normal serum } B_{12} .01 \mathrm{ml} \text { and } \\
\text { Serum } \mathrm{B}_{12}<150 \mu \mu \mathrm{g} . / \mathrm{ml} \text { and } \\
\text { normal serum folate.. }\end{array}$ & $\begin{array}{l}86 \\
34\end{array}$ & $\begin{array}{l}68 \\
15\end{array}$ & $\begin{array}{l}18 \\
19\end{array}$ \\
\hline Total & 120 & 83 & 37 \\
\hline
\end{tabular}

(b) Gastrectomy and Pregnancy.-Only four of these patients had had a gastrectomy and only three were pregnant; thus these factors appeared to be relatively unimportant in the present context.

(c) Gross Malnutrition.-Twenty-four, or $22.9 \%$ of the group, including two food cranks and six patients with nutritional oedema, were suffering from this condition. No patient with intestinal malabsorption was found.

(d) Physical Illness.-An increasing number of chronic physical illnesses are being associated with folate deficiency. Might not much of the present serum folate subnormality be due to concomitant physical illness apart from gross malnutrition ? Eighteen, or 17\%, of the patients were physically ill: 10 with cardiovascular disease, four with chronic bronchitis, two with Parkinsonism, and one each with myxoedema and pulmonary tuberculosis. There were no examples of myelosclerosis or rheumatoid arthritis.

Thus there is little support for the idea that chronic physical illness, malabsorption, and malnutrition are solely responsible for folate deficiency. On the other hand, of 105 patients with a low serum folate, as presently defined, only 21 patients were free of a recent drug history, poor nutritional status, gastrectomy, pregnancy, and chronic physical illness. A further five had a low serum $B_{12}$ level, so that only 16 patients were without any recognized or suspected cause of folate deficiency. These 16 patients constitute the "idiopathic" low folate group, and one would expect these patients to show in pure culture the link, if any, between the avitaminosis and the sort of mental disturbance associated with it. However, the patients came from a broad psychiatric spectrum covering schizophrenia, dementia, chronic alcoholism, endogenous and neurotic depression, neurosis, and psychopathy. Thus the "primary" or "idiopathic" deficiency was not obviously associated with any particular mode of psychiatric presentation.

(e) Chronicity of Mental Illness.-In assessing chronicity very frequent episodes of illness with only brief periods of remission between, say, a week or two were counted as one period of continuous illness. The following figures relate to the interval between onset of present illness and present hospitalization: ill for less than three months, $13.4 \%$ of patients ; three months to one year, $21.2 \%$; one to three years, $21.2 \%$; over three years, $44.2 \%$. The proportion of chronic cases is almost certainly much higher than for the generality of hospitalized psychiatric patients. These findings raised the interesting speculation of which came first, the chronicity 
or the folate deficiency? The long-term results of a trial of folic acid in the chronically mentally ill with a low serum folate might help to clear up the point.

There is evidence to suggest (Batata et al., 1967) that subnormal serum folate is a nonspecific result of illness in general. It could therefore be expected that low values would occur with greater frequency with increasing duration of illness, irrespective of diagnosis; thus the syndromes with the highest proportion of depressed levels would be those with the greatest excess of chronic cases. The above findings to some extent support this idea, but can any importance be allotted to diagnosis? If chronicity were decisive the patients with low serum folate could be expected to be uniformly chronic within each diagnostic subgroup. In fact, this was found to be not so. The individual diagnoses vary widely for proportions of chronic cases; thus $66 \%$ of the subnormal folate schizophrenics had been ill for more than three years compared with $28 \%$ of the endogenous depressives. The figures for neurotics and organics were $50 \%$ and $36 \%$ respectively. This finding suggests that diagnosis has an association with low serum folate independent of duration of illness.

\section{Discussion}

This study was not designed to be a comprehensive investigation of the aetiology and biochemistry of folate deficiency: it was intended to be a preliminary screening of a representative sample of major mental illness in a defined community of population 300,000-namely, Blackpool and the Fylde. Nevertheless, within these limits some aetiological pointers emerged and certain tentative inferences can be drawn. The most striking result was the frequency of subnormal serum folate at $22.5 \%$ of the patients surveyed. However, the assumption that a low serum level of folate invariably indicates a folate deficiency state is not justified. Falsely low levels can occur as the result of the in-vivo and in-vitro actions of certain drugs-a possibility supported by the present findings; phenothiazines can suppress test organisms in biological assay-for example, the influence of chlorpromazine on E. gracilis (Herbert et al., 1965)-and other laboratory artifacts can arise. In this investigation a normal control series was used to exclude some of these pitfalls. Empirically, a serum folate of $2 \mathrm{~m} \mu \mathrm{g} . / \mathrm{ml}$. was found to be a useful lower limit of normality, though this figure is much lower than commonly accepted levels-a finding suggesting that these levels are perhaps pitched too high.

Nevertheless, it is likely that these low serum folate values reflect a physiological imbalance, common in certain forms of mental illness, which has usually not progressed to megaloblastic anaemia. However, it does not automatically follow that the imbalance plays a causal part in psychiatric illness (see below).

The most striking associations with low serum folate were chronicity of illness, a history of medication, usually barbiturates, phenothiazines, or antidepressants, and the predominance of certain diagnoses-namely, epilepsy, endogenous depression, and organic brain syndromes. Also frequently present were malnutrition and, to a less extent, chronic physical illness. Apparently the duration of illness alone was not responsible for the associations with diagnosis.

Can drugs have played the decisive part in depressing the serum folate? The vast majority of these patients had had drugs, especially those recognized as serum-folate-depressantlike barbiturates; phenothiazines were also so prominent as to suggest they have a similar action. However, drugs, like chronicity, cannot be the whole explanation for the results, because schizophrenics and neurotics, the most chronic and probably the most medicated patients, relatively seldom had a low serum folate. On the other hand, endogenous depression and organic states, despite being of shorter duration and less likely to provoke prolonged courses of drugs, were unequivocally low in mean serum folate values. If duration of illness and drugs did not play a decisive part, what did ?
It was found that malnutrition and chronic physical debility, though not invariably associated with low serum folate, were evenly distributed among the low folate patients, irrespective of psychiatric diagnosis, with the exception of organic states which, not surprisingly, had a slight excess. The most widely accepted explanation for dietary deficiencies in psychiatric patients is apathy and self-neglect, secondary to the mental state. This is probably an oversimplified view. As Reynolds (1967) points out, mental illness, self-neglect, dietary deficiency, and further mental deterioration caused by the deficiency are linked in a vicious circle. But what caused the psychiatric condition in the first place ? An alternative explanation is that, in the same patient, vitamin deficiencies including folate can both cause and be caused by a psychiatric illness. The problem of investigating the interactions of these factors is thus a complex one, and prospective studies as well as long-term therapeutic trials of folic acid in patients with deficiency states are needed.

Epileptics are widely recognized as liable to folate deficiency largely due to the effects of anticonvulsant drugs (Malpas et al., 1966), but here again chronicity of illness and physical deterioration certainly contribute.

An interesting finding was the difference in the diagnostic patterns among the low serum folate and low serum $B_{12}$ patients. There is widespread agreement (Shulman, 1967) that organic psychosis is typical of vitamin $\mathrm{B}_{12}$ deficiency, the psychiatric counterpart of subacute combined degeneration of the cord. The present findings with regard to the low serum $B_{12}$ patients are in accord with this observation: surprisingly, the diagnostic associations of subnormal serum folate are radically different, especially with respect to depressive states. It can fairly be deduced that this association with functional rather than organic psychosis implies a difference in the underlying pathophysiological mechanism from that of vitamin $B_{12}$ deficiency.

Can the present investigation throw any light on the aetiological role of folate in mental illness? Despite our inability to establish a simple one-to-one relationship between "uncomplicated" low serum folate and a particular psychosyndrome, the present observations agree with Reynolds's (1967) suggestion that affective disturbances and organic psychoses are the typical psychiatric manifestations of folate deficiency, with a precision which is unlikely to be coincidental.

An unexpected finding was the significantly raised mean serum folate of the chronic alcoholics. That this may be more than a mere clinical curiosity is indicated by a report by Magnus (1966) describing a case of jejunal blind-loop syndrome, peripheral neuropathy, and high serum folate. He suggested that the raised serum folate might have caused the peripheral neuropathy even in the presence of normal serum $B_{12}$. The relevance of this observation for chronic alcoholism, a condition in which peripheral neuropathy is common, is obvious.

\section{Conclusion}

What are the practical implications of these results ? There are three: firstly, folate deficiency would appear to be common enough in the mentally ill to justify carrying out serum folate and $\mathrm{B}_{12}$ estimations as routine admission procedures ; secondly, it would be wise to treat patients with subnormal serum folate values with folic acid supplements, and, if indicated, cyanocobalamin, in the hope of securing mental as well as physical improvement; and thirdly, further exploratory studies as already suggested should be carried out.

\section{Summary}

Serum folate estimations were carried out on 423 psychiatric inpatients, consecutive admissions to a general hospital and a 
mental hospital unit, and 62 normal controls. Serum vitamin $B_{12}$ estimations were also done on 368 of the patients. Though patients and controls did not differ on mean serum folate, there were significantly more patients with values below $2 \mathrm{~m} \mu \mathrm{g} . / \mathrm{ml}$. ("low folate") than controls. Patients with epilepsy, organic psychoses, and endogenous depression had significantly lower mean serum folate, and chronic alcoholics significantly higher mean serum folate, than the controls; the former conditions also predominated among patients with low folate, a diagnostic pattern significantly at variance from that of patients with normal folate values and those with serum $B_{12}<150 \mu \mu \mathrm{g} . / \mathrm{ml}$. Low folate patients had more haematological abnormalities, including low serum $B_{12}$, than other patients; $75.2 \%$ had received drugs during the three weeks before admission, $22.9 \%$ showed evidence of malnutrition, $17 \%$ were physically ill, and $44.2 \%$ had been continuously ill for more than three years.

I wish to thank Drs. F. Yates, P. Harvey, and F. Hayes, Messrs. Orrell, Curd, Singleton, and Kilgarriff, and Sisters Hetherington and Morton for advice and co-operation; and Mrs. J. Taylor and Mrs. E. Jackson for clerical assistance.

\section{REFERENCES}

Batata, M., Spray, G. H., Bolton, F. G., Higgins, G., and Wollner, L. (1967). Brit. med. Ұ., 2, 667.

Forshaw, J. (1965). Ibid., 2, 1061.

- Moorhouse, E. H., and Harwood, L. (1964). Lancet, 1, 1004. Gough, K. R., Read, A. E., McCarthy, C. F., and Waters, A. H. (1963). Quart. 7. Med., 32, 243.

Grant, H. C., Hoffbrand, A. V., and Well, D. G. (1965). Lancet, 2, 763 Henderson, J. G., Strachan, R. W., Beck, J. S., Dawson, A. A., and Daniel, M. (1966). Ibid., 2, 809.

Herbert, V., Gottlieb, C. W., and Altschule, M. D. (1965). Ibid., 2, 1052. Klipstein, F. A. (1964). Blood, 23, 68.

Magnus, E. M. (1966). Lancet, 2, 341.

Malpas, J. S., Spray, G. H., and Witts, L. J. (1966). Brit. med. 7., $1,955$.

Read, A. E., Gough, K. R., Pardoe, J. L., and Nicholas, A. (1965). Ibid., $2,843$.

Reynolds, E. H. (1966). Communication to the 4th World Congress of Psychiatry, Madrid, 1966

(1967). Brit. F. Psychiat. 113, 681.

Shulman, R (1967). Ibid., 113, 241.

Waters, A. H., and Mollin, D. L. (1961). F. clin. Path., 14, 335.

\title{
Ascorbic Acid Nutrition in Gastroduodenal Disorders
}

\author{
MAX M. COHEN,* M.B., CH.B.; ANNE M. DUNCAN, $\dagger$ B.SC.
}

Frank clinical scurvy is a rare disease, but subclinical deficiency of ascorbic acid, as defined by low dietary intake of ascorbic acid and low blood levels, is common. Thus the significance of "subvitaminosis C" has been the subject of controversy since it was first described by Hess (1917). However, it is probably now accepted that, while under normal circumstances a low intake of ascorbic acid is harmless (Dahlberg, Engel, and Rydin, 1944), at times of stress, when there is increased utilization of ascorbic acid by the tissues generally (Faulkner and Taylor, 1937) and especially by wounded tissues (Crandon, Landau, Mikal, Balmanno, Jefferson, and Mahoney, 1958), dietary deficiency may render the patient vulnerable to infection (Heise and Martin, 1936) and the low blood ascorbic acid level may make the surgical patient more liable to wound dehiscence (Crandon, Lennihan, Mikal, and Reif, 1961).

Attention has recently been drawn to the low levels of leucocyte ascorbic acid seen in large numbers of surgical patients (Crandon et al., 1961), in elderly patients (Bowers and Kubik, 1965), and particularly in patients with peptic disorders (Cohen, 1967).

The fundamental importance of vitamin $C$ in the healing process has been demonstrated in guinea-pigs (Bourne, 1944 ; Penney and Balfour, 1949 ; Gould, 1958 ; Ellis, Harrison, and Hugh, 1965) and in humans (Hunt, 1941 ; Boyd and Campbell, 1950), the two animal species known not to synthesize ascorbic acid. It is therefore important to understand the significance of the low blood levels of ascorbic acid consistently found in patients with peptic ulcer (Harris, Abbasy, Yudkin, and Kelly, 1936 ; Platt, 1936 ; Archer and Graham, 1936; Lazarus, 1937 ; Portnoy and Wilkinson, 1938), as in these patients surgery is often the treatment of choice.

In this investigation we have attempted to assess the extent of ascorbic acid deficiency in surgical patients, and in particular in those with duodenal ulcer, using the leucocyte ascorbic acid level, as this is now accepted as the best available index of ascorbic acid nutrition (Bartley, Krebs, and O'Brien, 1953), and to relate these findings to dietary intake of ascorbic acid.

\footnotetext{
- Department of Surgery, Glasgow Royal Infirmary. Present appointment: Surgical Registrar, Western Infirmary, Glasgow W.1. † Department of Biochemistry, Glasgow Royal Infirmary, Glasgow C4.
}

\section{Method}

Leucocyte ascorbic acid levels were estimated by the method of Denson and Bowers (1961). Particular care was taken to avoid delays of more than several minutes between venepuncture and beginning the initial fractionation of the blood, as white blood cells take up ascorbic acid from the plasma on standing. Simultaneous estimations were made of the white blood cell count and platelet count to allow any necessary conversion factor to be applied (Gibson, Moore, and Goldberg, 1966) ; but in fact all of these counts fell within the accepted normal range and thus no conversion factor was necessary. The levels of ascorbic acid quoted subsequently represent the total ascorbic acid present in the white cells plus the platelets, though conventionally expressed as microgrammes per hundred million white blood cells ( $\mu$ g. $/ 10^{8}$ W.B.C.).

The leucocyte ascorbic acid levels were estimated in 14 normal healthy young adults, all of whom were known to have an intake of ascorbic acid of at least $30 \mathrm{mg}$./day, the level of intake recommended by the Medical Research Council (Bartley et al., 1953) and adopted by the British Medical Association.

A random sample of 50 patients admitted to a general surgical unit in a large city teaching hospital was investigated. All were admitted during November or December, a time of year when the autumn peak of ascorbic acid nutrition (National Food Survey Committee, 1966) would still be reflected in the leucocyte ascorbic acid level and above average levels could reasonably be expected. Dietary histories were obtained from all patients and normal subjects by one of us (M.M.C.) using a questionary based on the tables of McCance and Widdowson (1960).

Of the 50 patients investigated 14 were found to be suffering from some gastroduodenal disorder, and in all 14 the diagnosis was confirmed at laparotomy. Fourteen surgical patients with no known alimentary disease, matched for age and sex, were used as controls.

Nine of the 14 patients with gastroduodenal disorders had duodenal ulcer alone; all were treated surgically by total vagotomy and pyloroplasty. Eight of them were reviewed five months after surgery (one patient being lost to follow-up). 